\title{
Socio-Technical Knowledge Management and Epistemological Paradigms: Theoretical Connections at the Individual and Organisational Level
}

\author{
Matthew Jelavic \\ University of Ontario Institute of Technology \\ Oshawa, Ontario, Canada
}

matthew.jelavic@uoit.ca

\begin{abstract}
This paper provides an evaluation of the literature pertaining to the autopoietic, connectionist, and cognitivist epistemological paradigms. These paradigms exist at the individual and organisational level through diametrically opposed functionalist versus interpretive and integrative sociotechnical knowledge management perspectives. The alignments of individual and organisational epistemologies are essential to the effectiveness of a knowledge management system. Knowledge management should consider the roots of knowledge theoretically in order to share or manage knowledge dissemination successfully in organisations. The term 'knowledge sharing' has been emphasised and discussed comprehensively through its epistemological influential factors. This paper concludes the development of a Knowledge Management Epistemological Synthesis Model (KM-ES Model) and a comprehensive discussion and conclusion section focussing on the implications of epistemological influences on the knowledge management system of an organisation. The results from this study provide both researchers and academicians with a clear understanding of the interplay between epistemologies and a foundation for establishing an effective organisational knowledge management system.
\end{abstract}

Keywords: socio-technical, knowledge management, knowledge sharing, epistemology, cognitivist, connectionist, autopoietic, functionalist, interpretive, KM-ES Model

\section{Introduction}

As a society moves from the industrial into the information age, knowledge is becoming an everincreasing competitive advantage and prime facilitator behind the competitive success of global organisations (Apostolou \& Mentzas, 2003; Bhagat, Kedia, Harveston, \& Triandis, 2002; Bhardwaj \& Monin, 2006; Bohn, 1994; Bukowitz, Williams, \& Mactas, 2004; Collison \& Parcell,

Material published as part of this publication, either on-line or in print, is copyrighted by the Informing Science Institute. Permission to make digital or paper copy of part or all of these works for personal or classroom use is granted without fee provided that the copies are not made or distributed for profit or commercial advantage AND that copies 1) bear this notice in full and 2) give the full citation on the first page. It is permissible to abstract these works so long as credit is given. To copy in all other cases or to republish or to post on a server or to redistribute to lists requires specific permission and payment of a fee. Contact Publisher@InformingScience.org to request redistribution permission.
2004; De Long \& Fahey, 2000; Drucker, 1993; Grant, 1996; Mason, 2007; Nonaka, 1991; Nonaka \& Takeuchi, 1995; Nonaka \& von Krogh, 2009; Zack, 1999). This progressive shift of focus from physical to knowledge resources has led to the development of the knowledge management discipline within the fields of business administration and management science. B. Gupta, Iyer, and Aronson (2000) define 
knowledge management as a process that aids organisations in finding, selecting, organising, disseminating, and transferring information and expertise to support necessary activities such as problem solving, learning, strategic planning, and decision making within the organisation. Knowledge management is also recognised as an activity that supports the generation, growth, application, and sustainability of intellectual capital in organisations (Marr, Gupta, Pike, \& Roos, 2003; Marr \& Schiuma, 2001), intellectual capital being defined as an organisation's collective knowledge, expertise, experience, and associated intangible assets (Klein, 1998; Marr et al., 2003; Marr, Schiuma, \& Neely, 2002; Pan \& Scarbrough, 1999; Teece, 2000).

Philosophically, knowledge management is often approached from two diametrically opposed, and one integrative perspective: (1) interpretive versus (2) functionalist and (3) the sociotechnical perspective. These three perspectives are influenced, and take influence from, certain epistemologies that prevail at both the individual and group level: autopoiesis, connectionism, and cognitivism. As a hybrid and multidisciplinary area of study, knowledge management is a field that crosses diverse disciplines, such as information systems and psychology, which is conceptually complex consisting of many issues and viewpoints, ranging from the nature of knowledge itself to its most effective method of transfer (Collison \& Parcell, 2004; Hart \& Warne, 2006; Liew, 2007; Nonaka \& von Krogh, 2009; Smith, 2004). These complexities place the field within the interests of information systems researchers, psychologists, management scientists, and practitioners, with debate focussed on methods of approach (i.e., technological versus social) and, often, definitions of what specific terms actually mean (i.e., knowledge versus information and data). Conceptual frameworks of what constitutes a 'knowledge management system' and the definition of 'information' and its distinction from 'knowledge' vary across these disciplines. In the interest of narrowing this spectrum of methods and definitions, the focus of this particular analysis will be the interrelationships that exist between concepts in knowledge management, focussing on socio-technical systems, cognitive perspectives, and influences on knowledge management that include individual and organisational epistemologies. An understanding of these interrelationships allows organisations to establish effective knowledge management systems that align with prevailing individual or group perspectives on knowledge sharing. Knowledge sharing can be broadly defined as an exchange of knowledge from giver to receiver with socio-cultural factors and organisational structures as influencing factors (Lin, 2008; Usoro \& Kuofie, 2006). Organisational management can benefit from analysing the relationship between current organisational dynamics, knowledge sharing, and management objectives as they interrelate with culture (De Long \& Fahey, 2000; Usoro \& Kuofie, 2006). Therefore, this study aims to further analyse these interrelationships and provide a holistic understanding of the influential factors to knowledge management.

\section{Cognitivism, Connectionism and Autopoiesis: A Triumvirate of Epistemologies Related to Knowledge Management}

Epistemology is a branch of philosophy that deals with the study of knowledge. It is derived from the Greek word episteme (i.e., knowledge) and logos (i.e., theory, reason, study, and thought). Montague (1962) described epistemology as the extent to which things and qualities within the world are reliant on their existence as relatable objects to a knower or subject matter. The concept of organisational epistemology was introduced by von Krogh, Roos, and Slocum (1994) as "the theory on how and why organisations know" (p. 53). Extending this concept of organisational epistemology, Venzin, von Krogh, and Roos (1998) distinguished three epistemologies that would lead to further research in the area of organisational theory from an epistemological perspective: (1) cognitivist, (2) connectionist, and (3) autopoietic. Although Venzin et al. (1998) distinguished the cognitivist, connectionist and autopoietic epistemologies within the 
framework of practice, the cognitivist epistemology was originally represented by Simon (1982), the connectionist by Kogut and Zander (1995), and the autopoietic by Maturana and Varela (1980). These epistemologies would later be further developed by Marr et al. (2003) and Marr (2004) to apply to knowledge management approaches and analysis. As important influencing factors, the social differences that exist between societal cultures affect these three epistemologies and the nature of cognitive processes (Hofstede, Hofstede, \& Minkov, 2010; Mason, 2007; Nisbett, Peng, Choi, \& Norenzayan, 2001). These social differences are based on personal value systems that take impetus from macro-level socio-cultural, economic, political, and technological influences (Ralston, 2008). The inclination towards epistemological paradigms is grounded in these macro-level factors and personal value systems and perspectives. As such, these social differences need to be taken into account for knowledge creation, knowledge transfer, and knowledge management processes (Andriessen \& van den Boom, 2007; Ang \& Massingham, 2007; De Long \& Fahey, 2000). Since the knowledge management initiative within an organisation is both a social and technical undertaking (Coombs, Knights, \& Willmott, 1992; Pan \& Scarbrough, 1998; Rus, Lindvall, \& Sinha, 2001), the matching of the individual and the organisational epistemology to this system will yield a more effective implementation and, therefore, improve performance (Marr et al., 2003). This would be especially important in situations where organisations are spread across different countries and different cultures and utilise the same knowledge management system for all branch locations. The understanding of these social differences, cognitive phenomena, and epistemological assumptions can aid in the effective management of knowledge within an organisation and, indeed, should be the starting point of a knowledge management initiative (Limone \& Bastias, 2006; Roos, 2005). Figure 1 indicates the synthesis and visual comparison of the three classes of epistemology.

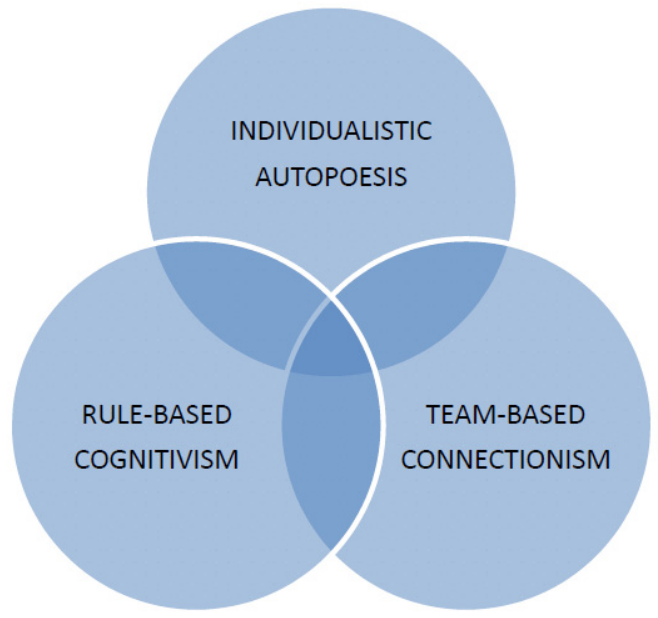

Figure 1: Classes of Epistemology (Adapted from Marr et al., 2003)

\section{Cognitivism: Perspectives from the Machine}

The cognitivist epistemology has its roots in the mid 1950s; it equates knowledge with information and data and assumes that organisations view knowledge as abstract, task specific, and directed towards problem solving (Limone \& Bastias, 2006; Marr et al., 2003; Roos, 2005; Sveiby, 2001). This view gave rise to the underlying theory behind the modern field of cognitive science (Limone \& Bastias, 2006). In accordance with Varela (1992), cognitivists assume that the goal of any cognitive system is to create the most accurate representation of what already exists in the world. As organisations increasingly collect, process, and store data and information, the cognitivist perspective believes that a more accurate representation of reality will occur. This assimilation and codification of knowledge is seen as a primary knowledge development activity, and this 
knowledge can be separated from individuals within the organisation (Marr, 2004). Cognitivists see knowledge management more from the perspective of information systems, databases, and knowledge structures, and believe that knowledge is developed and managed according to universal and standardised rules. Societal or organisational culture and other social factors are removed from the equation or disregarded outright (Holden, 2002). This cognitivist paradigm falls within the functionalist perspective of Schultze (1998). The transferability of knowledge is of key importance to cognitivists (Marr et al., 2003) and is considered the most dynamic aspect of the knowledge transfer process (Haghirian, 2003). A great deal of literature within the strategic management field is based on the cognitivist view of information processing and knowledge structures (von Krogh et al., 1994); its origins of approach are based upon information theory and the approach of knowledge management from a technological perspective (Beamish \& Armistead, 2001; Venzin et al., 1998). This cognitivist perspective is based in the tradition of western management where the organisation is viewed primarily as an information processing machine and knowledge is viewed as explicit (Nonaka, Toyama, \& Konno, 2000). Explicit knowledge is methodical, formal, and systematic and can be communicated, transferred, and shared in the form of hard data, codified procedures, product specifications, scientific formulas, or computer programs (Bukowitz \& Williams, 1999; Collison \& Parcell, 2004; Gourlay, 2006; Johannessen, Olaisen, \& Olsen, 2001; Nonaka, 1991; Nonaka \& Takeuchi, 1995; Nonaka \& Toyama, 2003; Pan \& Scarbrough, 1999; Venters, 2002).

\section{Connectionism: Technical, Yet Social}

Connectionists are analogous to cognitivists in their view on information processing as the basic activity of the knowledge management initiative; however, in their view there are no universal rules governing the acquisition and management of knowledge (Marr et al., 2003; Sveiby, 2001). This connectionist approach focuses on the concept that a network will emerge where selforganisation of the elements will play a pivotal role (Limone \& Bastias, 2006). Senge (1990) defines the team as the fundamental learning group within an organisation. Hence, the rules governing knowledge are team-based and vary depending on the locale and situation and depend on communication (Marr, 2004). Organisations are primarily viewed as means to aid in the transfer of knowledge and, as such, are more efficient than the individual for knowledge transfer. Less technically centralised than cognitivists, connectionists focus on the flow of information among self-managing groups within an organisation that considers a team to be the primary holder of information (Marr et al., 2003). The domain of the connectionist paradigm is positioned between the interpretive and functionalist perspectives (Schultze, 1998). Presented at an individual level, this paradigm is similar to the socio-technical perspective of knowledge management as developed by Pan and Scarbrough (1999), which was originally presented at an organisational level. Both the connectionist paradigm and the socio-technical perspective on knowledge management exist at the juncture of the functionalist and interpretive perspectives. As a developed form of information theory, the connectionist paradigm focuses on information and communication technologies (ICTs) as tools designed around groups that share similar systems of interpretation (Skok \& Kalmanovitch, 2005; Venzin et al., 1998).

\section{Autopoiesis: Human Primacy}

Autopoietics view knowledge as socially-constructed, context-sensitive, and dependent on history (von Krogh et al., 1994). ICTs are viewed as communications tools that assist in the identification of individuals that possess sought-after knowledge for the purposes of transfer through an interpretive personalisation strategy (Skok \& Kalmanovitch, 2005). As organisations are open to the influx of data and closed to the exodus of knowledge, autopoietics do not view knowledge as abstract but rather embodied in the individual (von Krogh et al., 1994). Since knowledge is internalised and based on individual rules, the transmission of knowledge is difficult due to internal 
and individual interpretation. This type of internalised knowledge is generally referred to as tacit knowledge within the knowledge management literature. Tacit knowledge is deeply rooted in the personal knowledge possessed by an individual and, since it is very difficult to formalise, it is difficult to communicate to others (Nonaka, 1991). It may also be contained as structured knowledge within the established routines of organisations and is not inclined to be transmitted or reproduced easily (Collison \& Parcell, 2004; De Long \& Fahey, 2000; Howitt, 1996). This paradigm allows autopoietics to develop individual knowledge whilst respecting the same process in others; this view is very similar to Polanyi's (1958) concept of personal knowledge and within the domain of the interpretive perspective as defined by Schultze (1998). Rooted in philosophical, psychological, and sociological concepts (Venzin et al., 1998), autopoietics allow the liberty for the individual interpretation of information (Marr et al., 2003), and their knowledge is connected to observation (von Krogh et al., 1994). The influence of social and cultural influences, both societal and organisational, is expected and respected. The autonomy of individual organisational members provides an environment that increases the chances and opportunities for motivating individuals to generate new knowledge within this autopoietic epistemological environment (Nonaka et al., 2000). The concept of this autopoietic epistemology is consistently aligned with egalitarianism and managerial decentralisation, allowing groups to manage themselves and exist within an organisational social system. Table 1 summarises and compares the three epistemological notions of knowledge.

Table 1: Cognitivist, Connectionist, and Autopoietic Notions of Knowledge (Adapted from Venzin et al., 1998)

\begin{tabular}{|l|l|l|l|}
\hline Notions of & Cognitivism & Connectionism & Autopoiesis \\
Knowledge & $\begin{array}{l}\text { Knowledge is a distinct, } \\
\text { fixed and codifiable entity } \\
\text { that can be universally } \\
\text { stored in ICTs and physical } \\
\text { documentation, allowing it } \\
\text { to be easily shared across } \\
\text { an organisation. }\end{array}$ & $\begin{array}{l}\text { Knowledge resides in the self- } \\
\text { organised connections of } \\
\text { teams, and is dependent on } \\
\text { the state of this network of } \\
\text { interconnected relationships. } \\
\text { There are no universal rules } \\
\text { regarding its transfer. }\end{array}$ & $\begin{array}{l}\text { hocial system and is } \\
\text { specific. It is not easily } \\
\text { shared, ond not directly } \\
\text { through discussions and } \\
\text { socialisation. }\end{array}$ \\
\hline
\end{tabular}

\section{The Functionalist versus Interpretivist Perspectives on Knowledge Management}

In accordance with Schultze (1998), functionalists pursue ontology of realism that assumes both facts and realities about the world exist and are waiting to be discovered. Furthermore, within the context of knowledge management, this perspective indicates that knowledge in an organisation has a discrete existence within an individual that can be "captured, manipulated, transferred, and protected" (Schultze, 1998, p. 160). A review of literature indicates that it is pervaded by the functionalist perspective, with knowledge being described within the context of intellectual capital and competitive advantage (Bohn, 1994; Grant, 1996; Klein, 1998; Marr et al., 2002; Pan \& Scarbrough, 1999; Teece, 2000). The cognitivist and, to a lesser extent, the connectionist epistemological paradigms, which draw similarities to the functionalist perspective, focus on the technological approach to knowledge management dominated by ICTs, databases, and intranets as primary solutions to collect, access, and share individual knowledge. The functionalist perspective is based on the idea that knowledge is an explicit object that manifests itself in a multitude of forms and locations, including individuals and cultures, yet can be detached, codified, and transmitted (Schultze, 1998).

The interpretive perspective is dominated by the philosophy that knowledge is dynamic and situated within social realities. Interpretivists believe that a more thorough understanding of social 
realities can occur by investigating the meanings individuals attribute to their own and others' actions (Schultze, 1998). The autopoietic and, to a lesser extent, the connectionist epistemological paradigms, the socio-technical perspective, and the interpretive perspective all view knowledge as socially constructed, embedded in social networks, and impervious to objective observation whilst coexisting with infrastructure and ICTs. These perspectives are open to social and cultural influences and full expectation of these influences are acknowledged.

Hansen, Nohria, and Tierney (1999) also identified a complementary taxonomy to the functionalist-interpretivist dichotomy that includes an IT-focussed 'codification' strategy and a peoplefocussed 'personalisation' strategy. Within the personalisation strategy, knowledge is closely tied to the individual and is shared mainly through person-to-person interaction. As such, the identification of the source of knowledge is important for its transfer. The codification strategy relies on knowledge that has been effectively separated from its originator and subsequently stored within databases that can be retrieved as required by anyone within the organisation, minimising the human element in its transfer. ICTs dominate the functionalist literature and would be placed within the definition of the codification strategy (Hansen et al., 1999).

From a socio-technical perspective, knowledge management is a strategy that allows for knowledge and routines to be formulated around organisational cultures and operational environments to develop efficiencies and improve member skills (Pan \& Scarbrough, 1999; Trist \& Bamforth, 1951). Contextual understanding must take into consideration the cultural, social, hierarchal, political, personal, and historical perspectives affecting how people, groups, and organisations interpret, evaluate, and process information (Coombs et al., 1992; Hofstede et al., 2010; Liew, 2007). As such, organisational structure and organisational culture are highly influencing factors in knowledge management and effective knowledge transfer (Chen, 2007; De Long \& Fahey, 2000; Haghirian, 2003; Usoro \& Kuofie, 2006). The underlying individual and, by extension, organisational epistemologies are deeply rooted in both societal and organisational culture, which influence the configuration of the interplay between social and technical systems within an organisation.

\section{A Synthesising Interpretation: Socio-Technical Perspectives on Knowledge Management}

The term 'socio-technical' was first created and used in the literature by Trist and Bamforth (1951) to describe an organisation as a duality of interrelated social and technological subsystems that functioned as a whole within its operating environment. Coombs et al. (1992) argued for the development of, and appreciation for, the social element of ICTs within an organisation, arguing that the two cannot be separated when studying organisations. Pan and Scarbrough (1999) further developed the concept by extending it into the knowledge management field and emphasised the social and technical factors in the way people perform work. Drawing upon the concept of knowledge as "socially constructed and embedded in social networks and communities of practice," Pan and Scarbrough (1999) defined knowledge management as "the capacity (or processes) within an organisation to maintain or improve organisational performance based on experience and knowledge" (p. 360). Organisational knowledge being socially constructed, both researchers proposed that it is shaped by the interaction of the technological and social elements of the organisation. For explicit knowledge transfer to be successful it must be enhanced with a tacit component, and for tacit knowledge transfer to be successful it must be complemented through explicit support (Fink \& Holden, 2007; Nonaka \& von Krogh, 2009). This mutual explicit-tacit dependency complements the position on the functionalist and interpretive interaction within socio-technical systems. 
Although a significant portion of the literature is focussed on the role of ICTs in knowledge management (Arambura \& Sáenz, 2007; Raub \& Ruling, 2001), Pan and Scarbrough (1999), Malhotra $(1998,2004)$ and Liew (2007) take a more holistic approach that encompasses and recognises the relationship between technological and sociological factors. Both Malhotra (1998) and Boisot (2002) made clear distinction between the information generated by computer systems and the knowledge that resides in the human mind. Thematically, they postulate that it may not be unreasonable to suggest that knowledge resides in the ICT user and not in the collection of information, and those ICTs are only tools that generate and process information rather than create knowledge. Rus et al. (2001) took a similar stance in that technology alone cannot manage knowledge and that only information about knowledge can be stored within an ICT system, with the human factor being required for transforming information into knowledge. Mason (2003) uses the term 'socio-technical' knowledge management as the interaction between physical resources, conceptual resources, and social and organisational processes.

Davenport and Prusak (1998) make the insightful statement that technology alone will not lead to a knowledge management culture within an organisation. This culture would be characterised by a value and practice paradigm that would longitudinally embrace knowledge sharing within an organisation. Without attention to the cultural factors related to knowledge sharing, ICTs are limited in their capabilities (Hart \& Warne, 2006). This progression of thought meshes closely with Pan and Scarbrough (1999) and Marr et al. (2003) and their connectionist and autopoietic positions on ICTs and human capabilities as partners within the knowledge management structure of an organisation. A general survey of the literature indicates that since knowledge develops from data and information, many organisations, scholars, and business leaders treat the terms knowledge management and information management as virtually synonymous (A. K. Gupta \& Govindarajan, 2000; Nonaka et al., 2000). This is often exacerbated by the repackaging of information processing software applications under the knowledge management label (Limone \& Bastias, 2006; Moffett, McAdam, \& Parkinson, 2003). These labels may be marketing attempts by the vendors to make these software products more attractive through the use of knowledge management buzzwords and promoted as solutions to problems that arise in the working environment (Limone \& Bastias, 2006; Lindvall, Rus, \& Sinha, 2002). By incorrectly identifying software tools as knowledge management tools, the term 'knowledge management' may be misused and overused within the applied management literature (Rus et al., 2001).

Carter and Scarbrough (2001) and De Long and Fahey (2000) indicate that IT-driven approaches may fail because the human element of sharing knowledge is often ignored. IT-based approaches to knowledge management need to be complemented by social methods. Hansen et al. (1999) pointed out that the wrong strategy or the pursuit of both the social and IT-based strategies at the same time can have a profound consequence and undermine organisational efforts to manage knowledge. It was further stated that the choice between functionalist-codification and interpretive-personalisation is of central importance when implementing a knowledge management initiative (Hansen et al., 1999). Since knowledge management is a complex process involving human and socio-cultural issues (Liew, 2007), the determination of the appropriate initial strategy for knowledge management is a crucial first step towards the development of an effective organisational system.

\section{Organisational Layering: The Interaction of Technology, Social Relations and Culture}

Pan and Scarbrough (1999) view knowledge management initiatives as socially constructed, shaped by the emergent interplay between technological and social factors and structured between tacit and explicit forms of knowledge within an organisational context. This is placed within three layers of interaction: (1) infrastructure: hardware/software that enables communications 
between nodes or members of the network, (2) infostructure: formal rules governing the exchange between actors in the network through metaphors and common language, and (3) infoculture: background knowledge, embedded in social relations surrounding work group processes, that defines the cultural constraints on knowledge and information sharing. These three layers of interaction are analogous to the three epistemological paradigms of (1) cognitivism, (2) connectionism and, (3) autopoiesis, developed by Marr et al. (2003).

Of particular importance is the term 'infoculture', which Pan and Scarbrough (1999) characterise as being socially determined and subjective, and its relationship to 'organisational culture' as generally defined in the broader literature. Schein (1985) defines organisational culture as a set of core values, artefacts, behavioural patterns, and norms which preside over the way members of an organisation interrelate. Hofstede et al. (2010) define organisational culture as "the collective programming of the mind that distinguishes the members of one organisation from another" (p. 344). This similarity between infoculture and organisational culture is of particular relevance because of the incorporation of values and practices within organisational culture and its importance to the determination of an effective knowledge management system. Travica (2005) presents a definition of infoculture that differs somewhat from the Pan and Scarbrough (1999) definition. Defining infoculture as stable beliefs and behaviours that refer to organisational ICTs, a more technicist approach is taken than the definition by Pan and Scarbrough (1999), yet the relationship to organisational culture remains. Travica (2005) includes ICTs as the primary focus around which an organisation's infoculture develops, aligning more with the space between the definition of infostructure and infoculture by Pan and Scarbrough (1999), proposing that ICTs influence the culture within an organisation. Both Pan and Scarbrough (1999) and Travica (2005) underscored the interplay between technology, social, and cultural elements within an organisation and drew analogies to organisational culture as defined in the literature.

The socio-technical perspective on knowledge management adopts a holistic approach that clearly emphasises the interrelatedness of the social and technical factors in human work (Pan \& Scarbrough, 1998). Müller, Spiliopoulou, and Lenz (2005) indicate that, since it is a sociotechnical system, the success of a knowledge management system is equally dependant on the users' culture and the technical system itself, whilst meeting the overall system goals. Figure 2 indicates the visual representation of the three layers of knowledge management introduced by Pan and Scarbrough (1998).

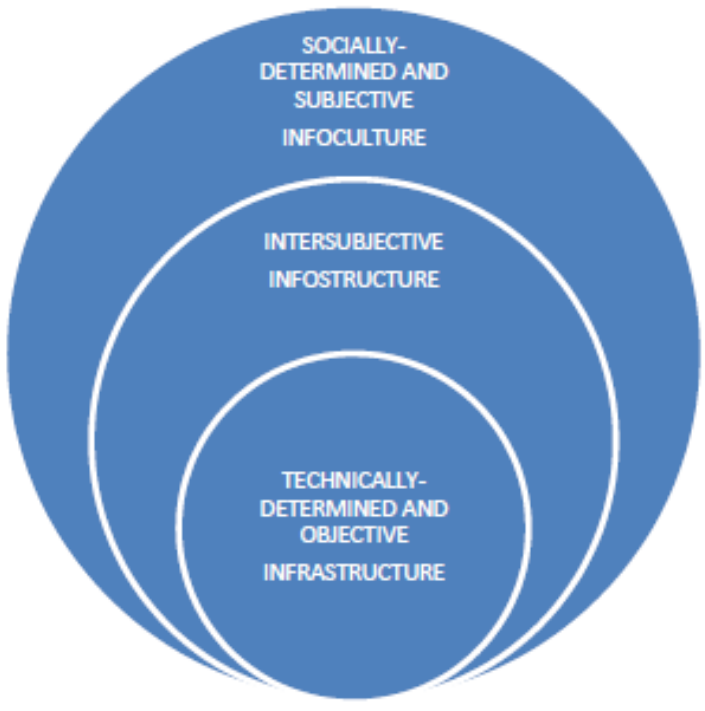

Figure 2: Socio-Technical Perspective on Knowledge Management (Adapted from Pan \& Scarbrough, 1998) 
Carter and Scarbrough (2001) acknowledged an inherent danger in taking a narrow, technicist approach to knowledge management and emphasised the importance of human factors. This perspective is a common point within the interpretive literature on knowledge management, often emphasising the support role of ICTs. A. K. Gupta and Govindarajan (2000) made a reference to the often mistaken belief that knowledge can be managed exclusively through the installation of sophisticated ICT systems as the "be-all and end-all of knowledge management" (p. 72). The 'informationalisation' of knowledge through ICTs is only one aspect of knowledge management, another element being organisational culture (Chen, 2007). Within the field of knowledge management, there is often an overemphasis on ICTs to the detriment of more people-oriented programmes (Moffett et al., 2003). By focussing on the technology of knowledge management, some organisations fail to focus on the methodology (Lawton, 2001). ICTs help to facilitate the storage and dissemination of knowledge that assist in knowledge creation and diffusion (Roberts, 2000). Yoo, Ginzberg and Ahn (1999) and Heier and Borgman (2002) equate Knowledge Management Systems (KMS) as information systems designed to facilitate knowledge management practice through infrastructure and environment. This indeed would be quite different than the other, less technicist, interpretation of knowledge management systems, systems of knowledge management which focus on more human-oriented, and technology processes and procedures for knowledge sharing. Initial knowledge management strategies focussed on ICT-based systems and solutions for the storage and transmission of explicit knowledge (Pauleen, $\mathrm{Wu}, \&$ Dexter, 2007). The literature is rich with research on knowledge management that takes an exclusively ICT-perspective on the discipline and treats knowledge management as a discipline of information systems or computer science, much of this literature from North America. Western perspectives on knowledge have a tendency to conceptualise knowledge in this explicit form (Nonaka et al., 2000). The western literature focuses on the implementation of ICTs at the expense of understanding information and knowledge as epistemological entities (Limone \& Bastias, 2006). There is, however, a significant portion of organisational knowledge that cannot be captured by these information systems; this knowledge resides tacitly in the processes and individuals within an organisation (Bhardwaj \& Monin, 2006). The focus of knowledge management has indeed

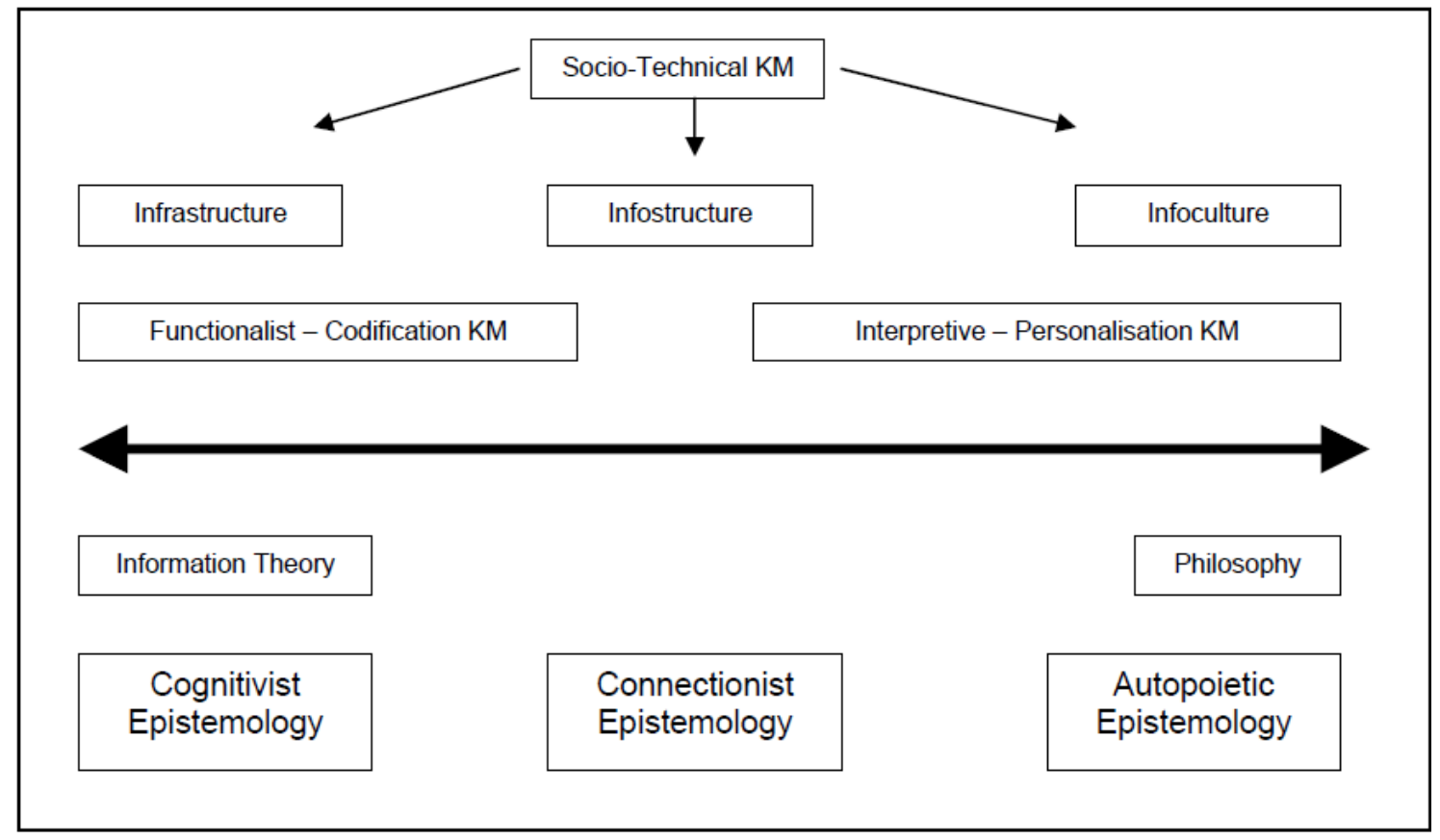

Figure 3: Knowledge Management Epistemological Synthesis Model (KM-ES Model) 
shifted to an increased awareness of the social and organisational aspects of knowledge management (Pauleen et al., 2007), which include elements of societal and organisational culture. Figure 3 shows a framework of the cumulative synthesis, visual representation, and summary of the interrelatedness of the various epistemological paradigms that were reviewed so far.

\section{Discussion}

The predominant epistemological paradigm within an organisation is a synthesis of organisational epistemology and the sum of individual epistemologies. As depicted in the KM-ES Model in Figure 3, the inclination of the individual organisation members to view knowledge management from one of the three discussed epistemological paradigms will influence the level of sociotechnical implementation and integration within the organisation as a whole. The depth of technological adaptation will be significantly influenced by individual and group epistemology focussing on autopoiesis, connectionism, or cognitivism. On the cognitivist end of the spectrum, these methods of knowledge sharing and management may take the form of formalised processes such as expert systems and knowledge databases. The autopoietic pole may work through more informal methods such as free-form discussion forums or unregulated meetings. Elements of these epistemological paradigms are evident in organisational practices such as document and database management, meeting dynamics, and management structure. The design of knowledge management systems requires a holistic analysis of epistemological and cultural factors and considerations of prevailing organisational practices. These systems are not designed in complete isolation within one philosophy whilst disregarding the other, as such hybrid systems that overlap epistemological paradigms are commonplace, yet a tendency will exist towards one philosophy or the other. The effectiveness of these systems will be highly dependent on the type of knowledge management structure that was initially developed within the organisation, compatibility being critical to ensure effective symbiosis between organisational and individual epistemologies.

Marr et al. (2003) conducted an investigative research study of six organisations to determine the relationship between individual epistemological paradigms and the organisational epistemological paradigm defined by the organisational knowledge management system. This delineation between an individual epistemological paradigm and an organisational epistemological paradigm acknowledges the distinction between the two and the recognition of an organisation as an entity capable of forming its own unique perspective on knowledge through the knowledge management system. The hypothesis of the Marr et al. (2003) study was that the alignment of organisational and individual epistemologies facilitates a specific approach to knowledge management. This research was divided into two service-based firms, two production-based firms, and two knowledge-based firms. The service-based firms showed the largest divergence between the viewpoints of the respondents and the organisational epistemology. The production-based firms were more aligned, whilst the knowledge-based firms were near individual-organisational epistemological matches. There was also an interesting connection between the size of the organisations and the epistemological paradigms. Larger organisations showed an inclination towards cognitivist information and document management systems whilst the smaller organisations had a better alignment between organisational and individual epistemologies. The greater the misalignment between the individual and organisational epistemology, the less relevance the individual placed on the knowledge management system, and the system was seen as ineffective and inefficient. In larger organisations with large and diverse departments, the research study indicated that a single organisation-wide knowledge management system may be unreasonable and would have to be tailored to distinct entities. The research study indicated that an understanding of epistemological issues was central in choosing a knowledge management approach. The epistemological inclination of organisational members can play a significant role in the adoptability and adaptability of a balanced socio-technical knowledge management system. 


\section{Conclusions and Contributions}

The epistemological paradigms within an organisation can be identified as a product of societal and organisational culture whilst influencing and taking influence from the practices within an organisation. Elements of these epistemological paradigms are evident in organisational practices such as document and database management, meeting dynamics, and management structure. The literature broadly supports the view that for the management of knowledge to be effective within an organisation there must be a reasonable matching of epistemologies of the established organisational mechanisms and the individual organisational members. The harmonising of organisational and individual epistemologies is possible if the underlying individual value systems are not characteristically different from the organisational culture to any great extreme. Polarisation of epistemologies will yield inefficient transfer of knowledge between individuals and groups within a particular organisation, resulting in poor knowledge management and knowledge sharing performance. An additional issue that may complicate the effective management and transfer of knowledge is departmental diversity within the organisation. It is possible that different departments within larger organisations, although grounded in the same societal and overall organisational culture, may exhibit differing epistemologies based on the nature of their function and the organisational practices under which each department operates. A research group may favour a more autopoietic perspective with unstructured methods of sharing and storing information whilst a production group may be more inclined towards cognitivism and the codification of all processes and procedures within ICTs. The matching of these individual and organisational epistemologies with appropriate social-technical systems is critical to effective knowledge transfer and management. A highly technical ICT implementation may be unnecessary for the research group, whereas unstructured meetings may be counterproductive for the production group.

This research contributes to the knowledge management literature by developing the KM-ES Model that represents the interplay of various epistemologies and their relationship to perspectives on knowledge management. Future research studies can test for individual and organisational epistemologies and utilise the KM-ES Model to determine the most effective level of sociotechnical integration and knowledge management implementation. The implementation of a purely technical, infrastructure-based system within an organisation that leans toward the interpretive-personalisation-autopoietic pole of the framework would prove difficult to implement. A purely technical system may not cater to the social relationships required by autopoiesis. Likewise, the implementation of a social, infoculture-based system may be incompatible to desired management objectives in a functionalist-codification-cognitivist organisation, with the social system lacking the structure and codification requirements of cognitivists. The KM-ES Model provides an excellent framework to work within for analysis, planning and implementation purposes of knowledge management within an organisation.

\section{References}

Andriessen, D., \& van de Boom, M. (2007). East is East, and West is West, and (n)ever its intellectual capital shall meet. Journal of Intellectual Capital, 8(4), 641-652.

Ang, Z., \& Massingham, P. (2007). National culture and the standardization versus adaptation of knowledge management. Journal of Knowledge Management, 11(2), 5-21.

Apostolou, D., \& Mentzas, G. (2003). Experiences from knowledge management implementations in companies of the software sector. Business Process Management Journal, 9(3), 354-381.

Arambura, N., \& Sáenz, J. (2007). Promoting people-focused knowledge management: The case of IDOM. Journal of Knowledge Management, 11(4), 72-81. 
Beamish, N. G., \& Armistead, C. G. (2001). Selected debate from the arena of knowledge management: New endorsements for establishing organizational practices. International Journal of Management Reviews, 3(2), 101-111.

Bhagat, R. S., Kedia, B. L., Harveston, P. D., \& Triandis, H. C. (2002). Cultural variations in the crossborder transfer of organizational knowledge: An integrative framework. Academy of Management Review, 27(2), 204-221.

Bhardwaj, M., \& Monin, J. (2006). Tacit to explicit: An interplay shaping organization knowledge. Journal of Knowledge Management, 10(3), 72-85.

Bohn, R. E. (1994). Measuring and managing technological knowledge. Sloan Management Review, Fall, 61-73.

Boisot, M. (2002). The creating and sharing of knowledge. In C. W. Choo \& N. Bontis (Eds.), The strategic management of intellectual capital and organizational knowledge. Oxford: Oxford University Press.

Bukowitz, W. R., \& Williams, R. L. (1999). The knowledge management fieldbook. London: Pearson Education Limited.

Bukowitz, W. R., Williams, R. L., \& Mactas, E. S. (2004). Human capital measurement. Research Technology Management, May-June, 43-49.

Carter, C., \& Scarbrough, H. (2001). Towards a second generation of KM? The people management challenge. Education + Training, 43(4/5), 215-224.

Chen, T. F. (2007). Knowledge management among Taiwanese high-tech industries and SMEs. In K. Hutchings \& K. Mohannak (Eds.), Knowledge management in developing economies: A cross-cultural and institutional approach (pp. 93-110). Cheltenham: Edward Elgar Publishing Limited.

Collison, C., \& Parcell, G. (2004). Learning to fly: Practical knowledge management from leading and learning organizations. Chichester: Capstone Publishing Limited.

Coombs, R., Knights, D., \& Willmott, H. C. (1992). Culture, control and competition: Towards a conceptual framework for the study of information technology in organizations. Organization Studies, 13(1), $51-72$.

Davenport, T., \& Prusak, L. (1998). Working knowledge - How organizations manage what they know. Boston, MA: Harvard Business School Press.

De Long, D. W., \& Fahey, L. (2000). Diagnosing cultural barriers to knowledge management. Academy of Management Executive, 14(4), 113-128.

Drucker, P. F. (1993). Post-capitalist society. Oxford: Butterworth Heinemann.

Fink, G., \& Holden, N. (2007). Cultural stretch: Knowledge transfer and disconcerting resistance to absorption and application. In D. J. Pauleen (Ed.), Cross-cultural perspectives on knowledge management (pp. 67-80). Westport, Connecticut: Libraries Unlimited.

Gourlay, S. (2006). Conceptualizing knowledge creation: A critique of Nonaka's theory. Journal of Management Studies, 43(7), 1415-1436.

Grant, R. M. (1996). Prospering in dynamically-competitive environments: Organizational capability as knowledge integration. Organization Science, 7(4), 375-387.

Gupta A. K., \& Govindarajan, V. (2000). Knowledge management's social dimension: Lessons from Nucor Steel. Sloan Management Review, 42(1), 78-81.

Gupta, B., Iyer, L. S., \& Aronson, J. E. (2000). Knowledge management: Practices and challenges. Industrial Management \& Data Systems, 100(1), 17-21.

Haghirian, P. (2003). Does culture really matter? Cultural influences on the knowledge transfer process within multinational corporations. Proceedings of the $11^{\text {th }}$ European Conference on Information Systems, 2003 
Hansen, M. T., Nohria, N., \& Tierney, T. (1999). What's your strategy for managing knowledge? Harvard Business Review, March-April, 106-116.

Hart, D., \& Warne, L. (2006). Comparing cultural and political perspectives of data, information, and knowledge sharing in organisations. International Journal of Knowledge Management, 2(2), 1-15.

Heier, H., \& Borgman, H. P. (2002). Knowledge management systems spanning cultures: The case of Deutsche Banks HRbase. Proceedings of the Xth European Conference on Information Systems ECIS, Gdansk, Poland.

Hofstede, G., Hofstede, G. J., \& Minkov, M. (2010). Cultures and organizations: Software of the mind (3rd ed.) New York: McGraw Hill.

Holden, N. (2002). Cross-cultural management: A knowledge management perspective. Harlow: Financial Times / Prentice Hall.

Howitt, P. (Ed.). (1996). The implications of knowledge-based growth for micro-economic policies (The Industry Canada Research Series, Volume 6.). University of Calgary Press.

Johannessen, J.-A., Olaisen, J., \& Olsen, B. (2001). Mismanagement of tacit knowledge: The importance of tacit knowledge, the danger of information technology, and what to do about it. International Journal of Information Management, 21(1), 3-20.

Klein, D. A. (1998). The strategic management of intellectual capital: An introduction. Boston: Butterworth-Heinemann.

Kogut, B., \& Zander, U. (1995). Knowledge and the speed of transfer and imitation of organisational capabilities: An empirical test. Organisation Science, 6(1), 76-92.

Lawton, G. (2001). Knowledge management: Ready for prime time? IEEE Computer, 34(2), 12-14.

Liew, C. L. (2007). From concept to context: Toward socio-cultural responsibility in the organization of knowledge. In D. J. Pauleen (Ed.), Cross-cultural perspectives on knowledge management (pp. 8194). Westport, Connecticut: Libraries Unlimited.

Limone, A., \& Bastias, L. E. (2006). Autopoiesis and knowledge in the organization: Conceptual foundation for authentic knowledge management. Systems Research and Behavioural Science, 23(1), 39-49.

Lin, W. B. (2008). The effect of knowledge sharing model. Expert Systems with Applications: An International Journal, 34(2), 1508-1521.

Lindvall, M., Rus, I., \& Sinha, S. (2002). Technology support for knowledge management. Fraunhofer Center for Experimental Software Engineering, College Park, and the Department of Computer Science, University of Maryland at College Park.

Malhotra, Y. (1998). Tools @ work. The Journal for Quality and Participation, 21(4), 58-60.

Malhotra, Y. (2004). Why knowledge management systems fail? Enablers and constraints of knowledge management in human enterprises. In C. W. Holsapple (Ed.), Handbook of knowledge management 1: Knowledge matters (pp. 577-599). Heidelberg: Springer-Verlag.

Marr, B. (2004). Measuring and benchmarking intellectual capital. Cranfield, UK: Centre for Business Performance, Cranfield School of Management.

Marr, B., Gupta, O., Pike, S., \& Roos, G. (2003). Intellectual capital and knowledge management effectiveness. Management Decision, 41(8), 771-781.

Marr, B., \& Schiuma, G. (2001). Measuring and managing intellectual capital and knowledge assets in new economy organisations. In M. Bourne (Ed.), Handbook of performance management. London: Gee.

Marr, B., Schiuma, G., \& Neely, A. (2002). Assessing strategic knowledge assets in e-business. International Journal of Business Performance Management, 4(2-4), 279-295. 
Mason, R. M. (2003). Culture-free or culture-bound? A boundary spanning perspective on learning in knowledge management systems. Journal of Global Information Management, 11(4), 20-36.

Mason, R. M. (2007). Culture: An overlooked key to unlocking organizational knowledge. In D. J. Pauleen (Ed.), Cross-cultural perspectives on knowledge management (pp. 21-34). Westport, Connecticut: Libraries Unlimited.

Maturana, H. R., \& Varela, F. J. (1980). Autopoeisis and cognition. London: Reidl.

Moffett, S., McAdam, R., \& Parkinson, S. (2003). An empirical analysis of knowledge management applications. Journal of Knowledge Management, 7(3), 6-26.

Montague, W. P. (1962). The ways of knowing or the methods of philosophy (6th impression). London: George Allen \& Unwin.

Müller, R. M., Spiliopoulou, M., \& Lenz, H-J. (2005). The influences of incentives and culture on knowledge sharing. Proceedings of the $38^{\text {th }}$ Hawaii International Conference on Systems Sciences.

Nisbett, R. E., Peng, K., Choi, I., \& Norenzayan, A. (2001). Culture and systems of thought: Holistic versus analytic cognition. Psychological Review, 108(2), 291-310.

Nonaka, I. (1991). The knowledge-creating company. Harvard Business Review, November-December, 96-104.

Nonaka, I., \& Takeuchi, H. (1995). The knowledge-creating company: How Japanese companies create the dynamics of innovation. New York: Oxford University Press.

Nonaka, I., \& Toyama, R. (2003). The knowledge-creating theory revisited: Knowledge creation as a synthesizing process. Knowledge Management Research \& Practice, 1(1), 2-10.

Nonaka, I., Toyama, R., \& Konno, N. (2000). SECI, Ba and leadership: A unified model of dynamic knowledge creation. Long Range Planning, 33(1), 5-34.

Nonaka, I., \& von Krogh, G. (2009). Tacit knowledge and knowledge conversion: Controversy and advancement in organizational knowledge creation theory. Organization Science, 20(3), 635-652.

Pan, S. L., \& Scarbrough, H. (1998). A socio-technical view of knowledge-sharing at Buckman Laboratories. Journal of Knowledge Management, 2(1), 55-66.

Pan, S. L., \& Scarbrough, H. (1999). Knowledge management in practice: An exploratory case study. Technology Analysis \& Strategic Management, 11(3), 359-374.

Pauleen, D. J., Wu, L-L, \& Dexter, S. (2007). Exploring the relationship between national and organizational culture, and knowledge management. In D. J. Pauleen (Ed.), Cross-cultural perspectives on knowledge management (pp. 3-19). Westport, Connecticut: Libraries Unlimited.

Polanyi, M. (1958). Personal knowledge. Chicago: University of Chicago Press.

Ralston, D. A. (2008). The crossvergence perspective: Reflections and projections. Journal of International Business Studies, 39(1), 27-40.

Raub, S., \& Ruling, C. C. (2001). The knowledge management tussle - Speech communities and rhetorical strategies in the development of knowledge management. Journal of Information Technology, 16(2), 113-130.

Roberts, J. (2000). From know-how to show-how? Questioning the role of information and communication technologies in knowledge transfer. Technology Analysis \& Strategic Management, 12(4), 429443.

Roos, G. (2005). An epistemology perspective on intellectual capital. In B. Marr (Ed.), Perspectives on intellectual capital: Multidisciplinary insights into management, measurement and reporting (pp. 196209). Oxford: Elsevier Butterworth-Heinemann. 
Rus, I., Lindvall, M., \& Sinha, S. S. (2001). Knowledge management in software engineering: A DACS state-of-the-art report. Fraunhofer Center for Experimental Software Engineering Maryland and The University of Maryland.

Schein, E. (1985). Organisational culture and leadership. San Francisco: Jossey-Bass.

Schultze, U. (1998). Investigating the contradictions in knowledge management. Proceedings of IFIP Working groups 8.2 and 8.6 joint Working Conference on Information Systems.

Senge, P. M. (1990). The fifth discipline: The art and practice of the learning organization. New York: Doubleday.

Simon, H. (1982). Models of bounded rationality (Vol. 2). MIT Press.

Skok, W., \& Kalmanovitch, C. (2005). Evaluating the role and effectiveness of an intranet in facilitating knowledge management: A case study at Surrey County Council. Information \& Management, 42(5), 731-744.

Smith, A. D. (2004). Knowledge management strategies: A multi-case study. Journal of Knowledge Management, 8(3), 6-16.

Sveiby, K-E (2001). A knowledge-based theory of the firm to guide strategy formation. Journal of Intellectual Capital, 2(4), 344-358.

Teece, D. J. (2000). Managing intellectual capital: Organizational, strategic and policy dimensions. Oxford: Oxford University Press.

Travica, B. (2005). Information politics and information culture: A case study. Informing Science: the International Journal of an Emerging Transdiscipline, 8, 211-244. Retrieved from http://www.inform.nu/Articles/Vol8/v8p211-244Travica.pdf

Trist, E. L., \& Bamforth, K. (1951). Some social and psychological consequences of the Longwall method of coal-getting. Human Relations, 4, 3-38.

Usoro, A., \& Kuofie, M. H. S. (2006). Conceptualisation of cultural dimensions as a major influence on knowledge sharing. International Journal of Knowledge Management, 2(2), 16-25.

Varela, F. J. (1992). Whence perceptual meaning? A cartography of current ideas. In F. J. Varela \& J. P. Dupey (Eds.), Understanding origins: Contemporary views on the origin of life, mind and society (pp. 235-264). Dordrecht: Kluwer Academic Publishers.

Venters, W. (2002). Literature review for c-sand: Knowledge management. Retrieved from http://www.csand.org/Documents/WP1001-02-KMLitRev.pdf

Venzin, M., von Krogh, G. \& Roos, J. (1998). Future research in knowledge management. In G. von Krogh, J. Roos, \& D. Kleine (Eds.), Knowing in firms: Understanding, managing and measuring knowledge. London: SAGE Publications.

von Krogh, G., Roos, J., \& Slocum, K. (1994). An essay on corporate epistemology. Strategic Management Journal, 15, 53-71.

Yoo, Y., Ginzberg, M. J., \& Ahn, J. H. (1999). A cross-cultural investigation of the use of knowledge management systems. Proceedings of the $20^{\text {th }}$ International Conference on Information Systems, Association for Information Systems.

Zack, M. H. (1999). Managing codified knowledge. Sloan Management Review, 40(4), 45-58. 


\section{Biography}

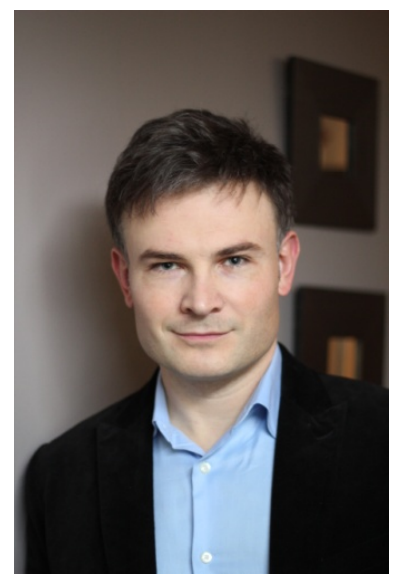

Dr. Matthew Jelavic holds a Doctorate in Business Administration from the Grenoble École de Management and a Master's Degree in Management Sciences from the University of Waterloo. Principal research interests include organisational theory, strategic management, knowledge management, and culture as they relate to international business and transitioning political economies. Dr. Jelavic conducts research and teaches within the Faculty of Business and Information Technology at the University of Ontario Institute of Technology and is National Vice-President of Education with the Canadian Institute of Management. Utilising integrative thinking, research plans include the development of advanced models of organisational theory to allow multinational enterprises to predict organisational performance issues, and develop and leverage effective entry strategies. 